\title{
ASSESSMENT OF THE EFFECTS OF REHABILITATION ON BALANCE IMPAIRMENT IN PATIENTS AFTER ISCHEMIC STROKE ACCORDING TO SELECTED TESTS AND SCALES
}

\author{
$\underline{\text { Magdalena Jaworska }}^{1)}$, Tomasz Tuzim $^{2)}$, Małgorzata Starczyńska ${ }^{3)}$, Magdalena Wilk- Frańczuk ${ }^{2)}$ \\ Agnieszka Pedrycz ${ }^{5}$ \\ 21 Military Spa-Rehabilitation Hospital in Busko-Zdrój, Poland \\ Vincent Pol University of Lublin, Poland \\ 3ealth Sciences Department, Jan Kochanowski University of Kielce, Poland \\ 4) Histology and Embryology Department with the Experimental Cytology Laboratory of Medical University in Lublin, Poland
}

\begin{abstract}
Cerebral stroke is one of the most important issues for modern medicine. Despite the fact that numerous activities have been undertaken for the purpose of raising awareness and significance of prevention, this condition still remains one of the main reasons behind disability. The objective of the work was to assess the effects of the type of therapy, age and period from the incident occurrence, on the progress of rehabilitation of imbalance and body stability observed in a group of researched patients, on the basis of results obtained according to the Berg Balance Scale, tandem balance test, Kwolek's loading symmetry index and Timed Up and Go test. The test group comprised of 55 post-stroke patients. The group consisted of 29 women (52.73\%) and 26 men $(47.27 \%)$. The average age of the subjects was 61.02 years (age range between 33-85 years). A number of the patients were subjected to rehabilitation with the use of classic kinesitherapy, whereas the remaining group underwent rehabilitation based on the proprioceptive neuromuscular facilitation method (PNF).

Key words: balance impairment, cebrebral stoke, psysiotherapeutic facilitation, functional test.
\end{abstract}

ARTICLE INFO

PolHypRes 2015 Vol. 51 Issue 2 pp. 55-66

ISSN: 1734-7009 eISSN: 2084-0535

Original article

DOI: $10.1515 / \mathrm{phr}-2015-0011$

Pages: 12, figures: 4 , tables: 5

Delivery date: 05.04 .2015 r.

page www of the periodical: www.phr.net.pl

Date of approval for print: 25.05 .2015 r.

Publisher

Polish Hyperbaric Medicine and Technology Society 


\section{INTRODUCTION}

According to the World Health Organisation, cerebral stroke is a condition characterised by circulation disorders leading to abrupt focal or general disturbances in brain functions which may persist for periods exceeding 24 hours or even result in death [1,2]. In Europe its incidence reaches 1 million people a year, of whom $1 / 3$ die.

The majority of survivors struggle with the sequelae of the illness till the end of their lives. Very often, patients become dependent on others. In Poland, incidence amounts to $175 / 100$ 000/year in relation to men and 125/100 000/year to women. Mortality rate for cerebral stroke is estimated at $104 / 100000 /$ year for men and 79/100 000/year for women.

Disability coefficient reaches ca. 70\%, whereas in highly-developed countries between 31$51 \%$ [3]. The most recognised classification of cerebral strokes involves its division into ischemic and haemorrhagic varieties. Haemorrhagic strokes occur as a result of blood extravasation from damaged vessels (subarachnoid or cerebral haemorrhage). Ischemic strokes are caused by closure of a vessel by an embolism or thrombus, which leads to insufficient blood flow in the region supplied by the occluded vessel [4].

Ischemic stroke takes four possible forms, namely: transient ischemic attack, reversible ischemic neurological deficit, progressive neurological deficit and complete ischemic stroke $[5,6]$. The problem of patients with hemiparesis involves disturbances in balance and postural stability. These conditions lead to limitation of selfreliance and have a significant effect on the deterioration of a patient's health status $[7,8]$. What is of key importance to post-stroke patients is undergoing immediate rehabilitation, which offers them the chance to recover and restore selfdependence. Rehabilitation should have a continuous and complex character and be adopted to the individual possibilities of each patient. Physiotherapists have numerous rehabilitation methods at their disposal, including: classic kinesitherapy and proprioceptive neuromuscular facilitation of movement (PNF).

Facilitation with the use of classic kinesitherapyy is based on motion treatment. Passive and active-passive exercises help to treat muscular contractures, dystrophies, limited joint mobility, as well as prevent bedsores and infections [9]. PNF therapy is based on the phenomenon of neuroplasticity, its main task being the restoration of lost functions. PNF is a method of activating undamaged muscles, increasing motor control, stability and mobility. Studies carried out in recent years indicate this method to be one of the most effective methods in the rehabilitation of patients after ischemic stroke $[7,8,10]$.

\section{MATERIAL AND METHOD}

\section{Group profile}

The research was performed in the period between May 2013 and April 2014 in SANUS Specialist Hospital in Stalowa Wola as well as in a private physiotherapy office. The test group comprised 55 poststroke patients, 29 women $(52.73 \%)$ and 26 men (47.27\%) (Fig. 1).

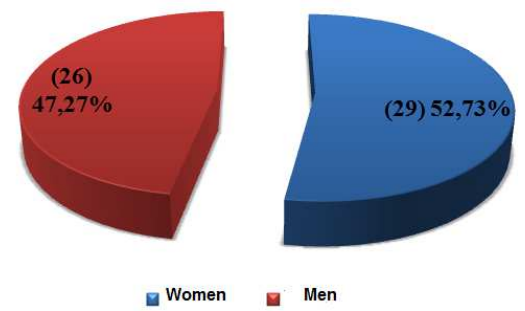

Fig. 1. Sex distribution in the test group

The average age of the subjects was 61.02 years (age range between 33-85 years). Subjects aged under 65 years old constituted $63.64 \%$ of the group, whereas those aged 65 and more 36.66\%. (Fig. 2). 


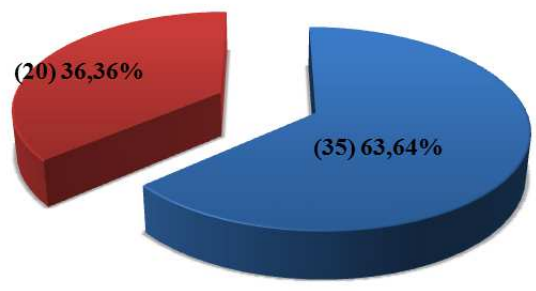

$\square<65 \square 65$ and more

Fig. 2. Age of subjects.

Average time from incident occurrence amounted to 1.32 years $(61.82 \%, n=34)$, the rest of the patients $(38.18 \%, n=21)$ struggling with the ailment for over a year (Fig. 3).

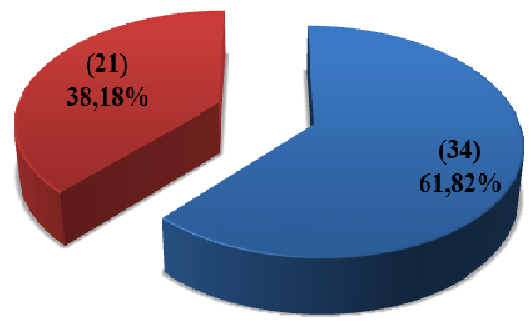

घ1. $\square 2$.

Fig. 3. Period from incident occurrence.

The subjects of the study were divided into two groups. The first group comprised patients (54.55\%, $\mathrm{n}=30$ ) undergoing classic kinesitherapy, whereas the second group consisted of patients $(45.45 \%, n=25)$ subjected to individualised rehabilitation programmes conducted on the basis of proprioceptive neuromuscular facilitation (PNF) (Fig. 4).
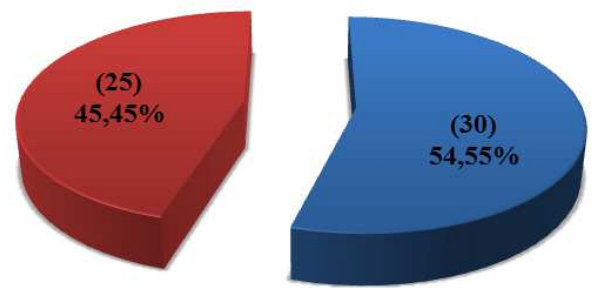

- Classical kinesitherapy

口PNF

Fig. 4. Rehabilitation type applied in the researched group.

Methodology of own research and the applied $\underline{\text { research tools }}$

The participants of the research were patients frequenting rehabilitation programmes granted by referral from specialist doctors: neurologists, neurosurgeons, orthopaedists. The conditions qualifying patients to participate in the research included: good current health status, rehabilitation or functional adaptation period, stable emotional state, ability to move and function daily with minimum assistance from another person and the ability to maintain a stable standing position, at least momentarily.

Rehabilitation in both researched groups lasted 4 weeks, at the frequency of 5 sessions per week. The duration of exercises was 1 hour a day. One person was responsible for carrying out both the therapy and later an examination of the patients.

The first group of 30 patients was subject to rehabilitation involving classic kinesitherapy. The therapy consisted of active-passive exercises as well as assisted exercises of the affected and seemingly affected side, balance exercises, and exercises with the use of gymnastic tools. As part of the exercises the patients were taught proper loading of the lower extremities for the purpose of consecutive reeducation of gait performed with the use of handrails.

The exercises included throughout the entire facilitation cycle were conducted by the same person. The second group of 25 patients was subjected to rehabilitation based on PNF philosophy. Therapy commencement involved determination of individual needs and expectations of each patient. Patients' disorders were defined with regard to daily activities.

Due to the character of the conducted research, each patient was asked whether they agreed with the statement that their priority involved improvement of balance and postural stability and gait reeducation. Rehabilitation of each patient was based on the 
hypothesis defining the reasons for having problems in everyday activities. In the case of the test group these included mainly spasticity, balance, absence of axiality in applying load on limbs, proprioception.

Moreover, the patients were subjected to an examination determining their level of participation performed on the first day and repeated after 4 days, 2 weeks and at the end of the 4-week of the rehabilitation programme. In the case of gait, it was determined which of the phases was the most disturbed, this becoming the focus of exercises (in the case where several of the phases were involved, it was attempted to improve each of them).

Tests based on the trial therapy allowed the estimation of mobility, stability, mobility stability and endurance of every patient. The exercises were conducted in low positions, starting from lying on the side and on the back, then in supported kneel (closed chain), sitting and standing positions. Determination of functional and structural objectives helped select proper movement patterns, for instance, for the pelvis (posterior depression), activity of lower extremities in proper synergies and techniques (e.g. flex, relax or rhythmic stabilisation) aiding their accomplishment.

Work on the stability of a standing position was carried out, for example, while lying on the healthy side with the foot of the affected limb pressed against the wall. The physiotherapist made a verbal command "foot to the wall" to the patient, whose task was to carry it out under their visual supervision. In the work on the stability of standing position while the patient performed a movement, what was very important was the reactive transfer of body weight on which the therapist worked with the use of sensory information delivered for statistical stability in a place where it was necessary. The therapy also involved the use of Thera-Band to transfer proprioceptive information.

The tests evaluating the efficiency of the conducted forms of therapy and their impact on balance parameter changes in the course of the whole facilitation programme were carried out on the first day of therapy and repeated 4 weeks later, i.e. on the last day of rehabilitation. Balance assessment was performed with the use of the following tools: Berg Balance Test, tandem balance test and Timed Up and Go test.

Berg Balance Test is a tool designed for the purpose of examining people with static and dynamic balance impairment. It contains 14 items, each assigned a different motor function typical for everyday life activities. The test evaluates the patient's balance in a sitting and standing position, with a gradual increase in the difficulty of performed tasks.

The activities are evaluated on a scale from 0 to 4 , with the maximum possible score of 56 .

The number of points scored allows the defining of the degree of self-sufficiency of a given patient. Patients were evaluated on

the performance of the following movements: shift from sitting to standing position; standing unsupported; sitting unsupported; shift from standing to sitting; transfers; standing unsupported with eyes closed; standing unsupported with feet together; picking up objects from the floor; standing on one leg; turning while standing; reaching forward with outstretched arms while standing; turning 360 degrees; placing feet on step; standing in one line; placing one foot behind the other.
Interpretation of results: $0-20$ wheelchair patient; 21-40 walks with support; 41-46 independent.

Tandem balance test is used to evaluate differences occurring in the load on lower extremities when in the standing position. The test was performed with the use of two identical bathroom scales with digital displays. The scales were separated from each other by 5 $\mathrm{cm}$, with the display in a position perpendicular to the edge of the foot.

The patient was allowed to be assisted by a physiotherapist while standing on the scales. In the course of testing the patient's shoulders were at the sides and the patient was asked to look forward. Mean deviation of less than 4-5 $\mathrm{kg}$ was deemed standard. The results obtained in the tandem balance test allowed the calculation of the loading symmetry index for lower extremities according to Kwolek. Correct values are included in the range between 1.00 and 1.15.

Timed Up and Go test. This test consisted in a patient's raising from a bed placed at a height suited to each patient, walking 3 meters and returning to the starting point. During task performance, physiotherapist measured the time needed by a given patient for its completion. Patients were allowed to use orthopaedic devices, such as a foot orthosis or, if necessary, a tripod. They were requested to cover the assigned distance in the shortest possible time but also in a manner that was safest for them.

\section{$\underline{\text { Statistical analysis }}$}

The analysis of results was carried out according to the statistical package PQStat ver. 1.4.2.324. The results of the analysed scales before and after rehabilitation were compared with the use of the t-student test for dependent variables. Depending on the type of therapy, sex, age or period elapsed from the incident, the results for the said scales were compared on the basis of the t-student test for independent variables.

Combined analysis was conducted with the use of analysis of variance. Interrelations between the scales were analysed by estimation of Pearson's linear correlation coefficients.

Significant test probability was assumed for the level of $\mathrm{p}<0.05$, and highly significant test probability for the level of $\mathrm{p}<0.01$.

$\underline{\text { Results }}$ 


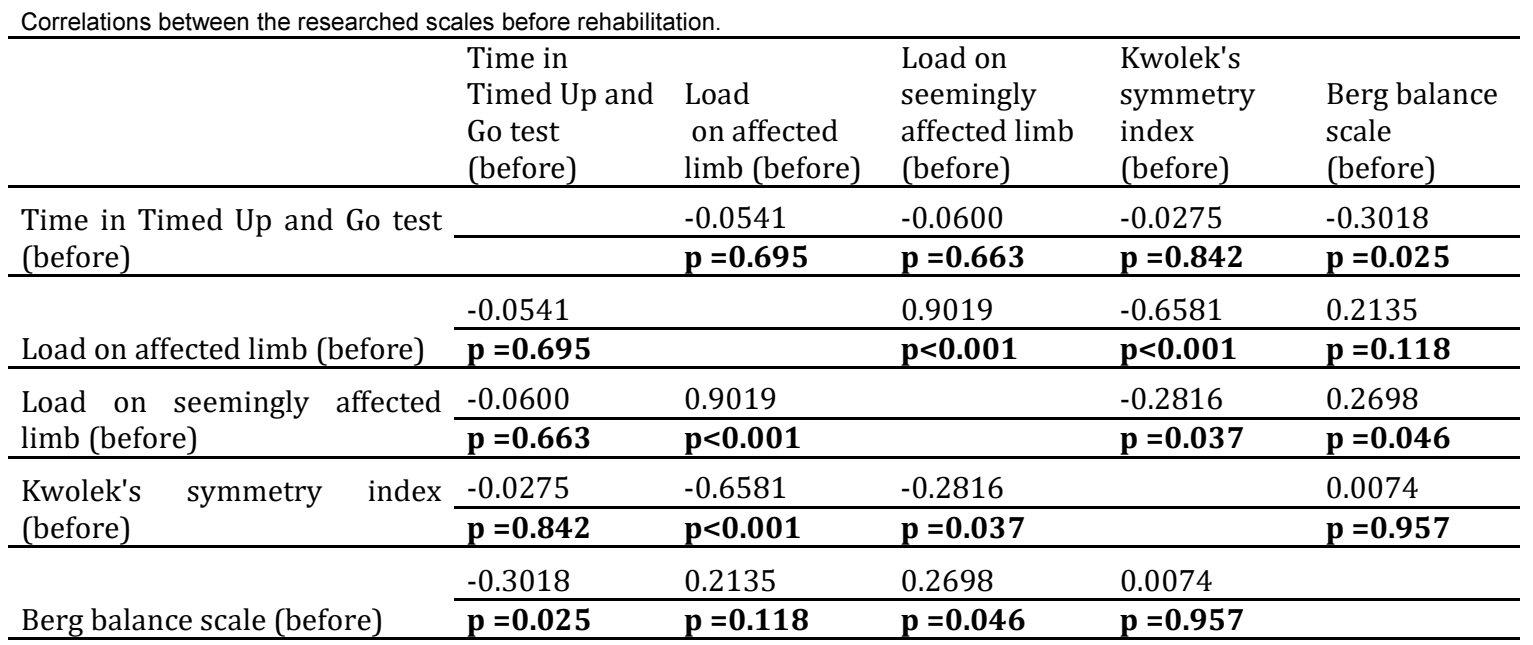

Times in the Timed up and Go test (before) were significantly negatively correlated with the results on the Berg balance scale (before). Load on affected limb (before) is highly significantly positively correlated with the load on seemingly affected limb (before), and highly significantly negatively correlated with Kwolek's symmetry index (before).

Load on the seemingly affected limb (before) is also significantly negatively correlated with Kwolek's symmetry index (before) and significantly positively with the Berg balance test (before) (Tab. 1).

Correlations between the researched scales after rehabilitation

\begin{tabular}{|c|c|c|c|c|c|}
\hline & $\begin{array}{l}\text { Time in } \\
\text { Timed Up } \\
\text { and Go test } \\
\text { (after) }\end{array}$ & $\begin{array}{l}\text { Load on } \\
\text { affected limb } \\
\text { (after) }\end{array}$ & $\begin{array}{c}\text { Load on } \\
\text { seemingly } \\
\text { affected limb } \\
\text { (after) }\end{array}$ & $\begin{array}{l}\text { Kwolek's } \\
\text { symmetry index } \\
\text { (after) }\end{array}$ & $\begin{array}{l}\text { Berg balance } \\
\text { test (after) }\end{array}$ \\
\hline \multirow{2}{*}{$\begin{array}{c}\text { Time in Timed Up and Go } \\
\text { test (after) }\end{array}$} & & -0.2855 & -0.1670 & 0.3536 & -0.4453 \\
\hline & & $p=0.035$ & $p=0.223$ & $p=0.008$ & $p=0.001$ \\
\hline \multirow{2}{*}{$\begin{array}{l}\text { Load on affected limb } \\
\text { (after) }\end{array}$} & -0.2855 & & 0.9002 & -0.5520 & 0.3162 \\
\hline & $p=0.035$ & & $\mathrm{p}<0.001$ & $\mathrm{p}<0.001$ & $p=0.019$ \\
\hline \multirow{2}{*}{$\begin{array}{l}\text { Load on seemingly } \\
\text { affected limb (after) }\end{array}$} & -0.1670 & 0.9002 & & -0.1412 & 0.2906 \\
\hline & $\mathrm{p}=0.223$ & $\mathrm{p}<0.001$ & & $\mathrm{p}=0.304$ & $p=0.031$ \\
\hline \multirow{2}{*}{$\begin{array}{c}\text { Kwolek's symmetry index } \\
\text { (after) }\end{array}$} & 0.3536 & -0.5520 & -0.1412 & & -0.1588 \\
\hline & $p=0.008$ & $\mathbf{p}<0.001$ & $p=0.304$ & & $\mathrm{p}=0.247$ \\
\hline \multirow{2}{*}{ Berg balance test (after) } & -0.4453 & 0.3162 & 0.2906 & -0.1588 & \\
\hline & $p=0.001$ & $p=0.019$ & $p=0.031$ & $\mathrm{p}=0.247$ & \\
\hline
\end{tabular}

Times in the Timed Up and Go test (after) are significantly negatively correlated with the load on affected limb (after) and highly significantly negatively correlated with Berg balance test (after), whereas they symetryczności Kwolka (po). are highly significantly positively correlated with Kwolek's symmetry index (after).

Load on the affected limb (after) is highly significantly positively correlated with the load on seemingly affected limb (after), and highly significantly negatively correlated with the results of Kwolek's symmetry index (after) and significantly positively correlated with the results in the Berg balance test (after). Load on seemingly affected limb (after) is significantly positively correlated with the results of the Berg balance test (after) (Tab. 2). 
Tab. 3

\begin{tabular}{|c|c|c|c|c|c|c|c|c|c|c|}
\hline & \multirow[b]{2}{*}{ Rehabilitation } & \multicolumn{9}{|c|}{ Descriptive statistics } \\
\hline & & 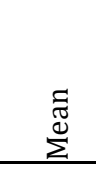 & 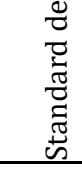 & $\begin{array}{l}\Xi \\
\Xi \\
\Xi \\
\Xi \\
\Xi\end{array}$ & 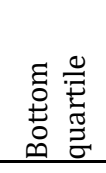 & 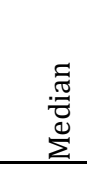 & 胥 & 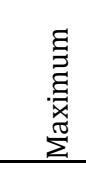 & & 2 \\
\hline \multirow{2}{*}{$\begin{array}{l}\text { Time in Timed Up } \\
\text { and Go test (change) }\end{array}$} & $\begin{array}{l}\text { classic } \\
\text { kinesitherapy }\end{array}$ & -1.68 & 0.69 & -3.15 & -2.03 & -1.82 & -1.04 & 0.00 & \multirow[t]{2}{*}{10.27} & \multirow[t]{2}{*}{$\mathrm{p}<0.0001$} \\
\hline & PNF & -5.19 & 1.72 & -9.81 & -6.11 & -5.02 & -3.81 & -2.61 & & \\
\hline \multirow{2}{*}{$\begin{array}{l}\text { Load on affected limb } \\
\text { (change) }\end{array}$} & $\begin{array}{l}\text { classic } \\
\text { kinesitherapy }\end{array}$ & 1.93 & 0.83 & 1.00 & 1.00 & 2.00 & 2.00 & 4.00 & \multirow[t]{2}{*}{-4.13} & \multirow[t]{2}{*}{$p=0.0001$} \\
\hline & PNF & 3.08 & 1.22 & 1.00 & 2.00 & 3.00 & 4.00 & 5.00 & & \\
\hline \multirow{2}{*}{$\begin{array}{l}\text { Load on seemingly } \\
\text { affected limb } \\
\text { (change) }\end{array}$} & $\begin{array}{l}\text { classic } \\
\text { kinesitherapy }\end{array}$ & -2.00 & 0.95 & -5.00 & -2.00 & -2.00 & -1.00 & -1.00 & \multirow[t]{2}{*}{3.98} & \multirow[t]{2}{*}{$\mathrm{p}=0.0002$} \\
\hline & $\mathrm{PNF}$ & -3.16 & 1.21 & -5.00 & -4.00 & -3.00 & -2.00 & -1.00 & & \\
\hline \multirow{2}{*}{$\begin{array}{l}\text { Kwolek's symmetry } \\
\text { index (change) }\end{array}$} & $\begin{array}{l}\text { classic } \\
\text { kinesitherapy }\end{array}$ & -0.16 & 0.10 & -0.52 & -0.19 & -0.14 & -0.10 & -0.05 & \multirow[t]{2}{*}{2.53} & \multirow[t]{2}{*}{$\mathrm{p}=0.0144$} \\
\hline & PNF & -0.23 & 0.08 & -0.46 & -0.28 & -0.20 & -0.17 & -0.11 & & \\
\hline \multirow{2}{*}{$\begin{array}{l}\text { Berg balance test } \\
\text { (change) }\end{array}$} & $\begin{array}{l}\text { classic } \\
\text { kinesitherapy }\end{array}$ & 1.73 & 0.94 & 0.00 & 1.00 & 2.00 & 2.00 & 4.00 & \multirow[t]{2}{*}{-12.95} & \multirow[t]{2}{*}{$\mathrm{p}<0.0001$} \\
\hline & $\mathrm{PNF}$ & 6.40 & 1.68 & 2.00 & 6.00 & 6.00 & 7.00 & 9.00 & & \\
\hline
\end{tabular}

In the PNF group the result improvement is much higher. Load on the seemingly affected limb (change) in the group facilitated with the classic kinesitherapy methods was on average $-2 \mathrm{~kg}$, whereas in the PNF group the mean value reached $-3.16 \mathrm{~kg}$. A highly significant difference was observed between the groups. In the PNF group the result improvement is much higher. Kwolek's symmetry index (change) in the group facilitated with classic kinesitherapy methods was on average $-0.16 \mathrm{pt}$, whereas in the PNF group the mean value reached -0.23 pt. A significant difference was observed between the groups. In the PNF group the resulting improvement is higher.

The Berg balance test (change) in the classic kinesitherapy group was on average $1.73 \mathrm{pt}$, whereas in the PNF group the mean value reached was $6.4 \mathrm{pt}$.

A highly significant difference was observed between the groups. In the PNF group the resulting improvement is much higher (Tab. 3). 


\begin{tabular}{|c|c|c|c|c|c|c|c|c|c|c|}
\hline & \multirow[b]{2}{*}{$\begin{array}{l}\text { Period from } \\
\text { incident } \\
\text { occurrence } \\
\text { 1-less than a } \\
\text { year } \\
2 \text {-more than a } \\
\text { year }\end{array}$} & \multicolumn{9}{|c|}{ Descriptive statistics } \\
\hline & & $\sum_{\Sigma}^{\Xi}$ & 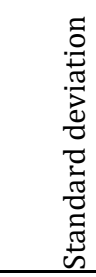 & 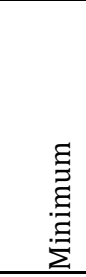 & 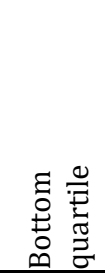 & 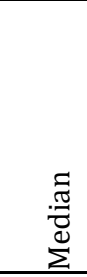 & 党 & 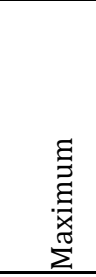 & $\mathbf{t}$ & $\mathbf{p}$ \\
\hline \multirow{2}{*}{$\begin{array}{l}\text { Time in Timed Up } \\
\text { and Go test } \\
\text { (change) }\end{array}$} & 1 & -3.13 & 2.08 & -8.11 & -4.53 & -2.32 & -1.66 & 0.00 & \multirow[t]{2}{*}{0.65} & \multirow[t]{2}{*}{$\mathrm{p}=0.5166$} \\
\hline & 2 & -3.52 & 2.33 & -9.81 & -4.92 & -3.01 & -1.68 & -0.73 & & \\
\hline \multirow{2}{*}{$\begin{array}{l}\text { Load on affected } \\
\text { limb (change) }\end{array}$} & 1 & 2.35 & 0.95 & 1.00 & 2.00 & 2.00 & 3.00 & 5.00 & \multirow[t]{2}{*}{-0.82} & \multirow[t]{2}{*}{$\mathrm{p}=0.4167$} \\
\hline & 2 & 2.62 & 1.47 & 1.00 & 2.00 & 2.00 & 4.00 & 5.00 & & \\
\hline \multirow{2}{*}{$\begin{array}{l}\text { Load on seemingly } \\
\text { affected limb } \\
\text { (change) }\end{array}$} & 1 & -2.44 & 0.99 & -5.00 & -3.00 & -2.00 & -2.00 & -1.00 & \multirow[t]{2}{*}{0.67} & \multirow[t]{2}{*}{$\mathrm{p}=0.5088$} \\
\hline & 2 & -2.67 & 1.53 & -5.00 & -4.00 & -2.00 & -2.00 & -1.00 & & \\
\hline \multirow{2}{*}{$\begin{array}{l}\text { Kwolek's } \\
\text { symmetry index } \\
\text { (change) }\end{array}$} & 1 & -0.18 & 0.08 & -0.36 & -0.21 & -0.17 & -0.13 & -0.05 & \multirow[t]{2}{*}{0.85} & \multirow[t]{2}{*}{$\mathrm{p}=0.3965$} \\
\hline & 2 & -0.21 & 0.12 & -0.52 & -0.28 & -0.18 & -0.12 & -0.06 & & \\
\hline \multirow{2}{*}{$\begin{array}{l}\text { Berg balance test } \\
\text { (change) }\end{array}$} & 1 & 3.44 & 2.52 & 0.00 & 2.00 & 2.00 & 6.00 & 9.00 & \multirow[t]{2}{*}{-1.47} & \multirow[t]{2}{*}{$\mathrm{p}=0.1488$} \\
\hline & 2 & 4.52 & 2.87 & 0.00 & 2.00 & 5.00 & 7.00 & 9.00 & & \\
\hline
\end{tabular}

Time in the Timed Up and Go test (change) in group 1 reached on average -3.13 sec., whereas in group 2 the mean result reached -3.52 . No statistical significance was observed between the groups. Load on affected limb (change) in group 1 was on average $2.35 \mathrm{~kg}$, whereas in group 2 the mean value reached $2.62 \mathrm{~kg}$.

No statistical significance was noted between the groups. Load on the seemingly affected limb (change) in group 1 was on average $-2.44 \mathrm{~kg}$, whereas in group 2 the mean value reached $-2.67 \mathrm{~kg}$.
No statistical significance was observed between the groups. Kwolek's symmetry index (change) in group 1 was on average $-0.18 \mathrm{pt}$, whereas in group 2 the mean value reached $-0.21 \mathrm{pt}$. No statistical significance was noted between the groups. The Berg balance test (change) in group 1 was on average $3.44 \mathrm{pt}$, whereas in group 2 the mean value reached 4.52 pt. No statistical significance was observed between the groups (Tab. 4). 
Tab. 5.

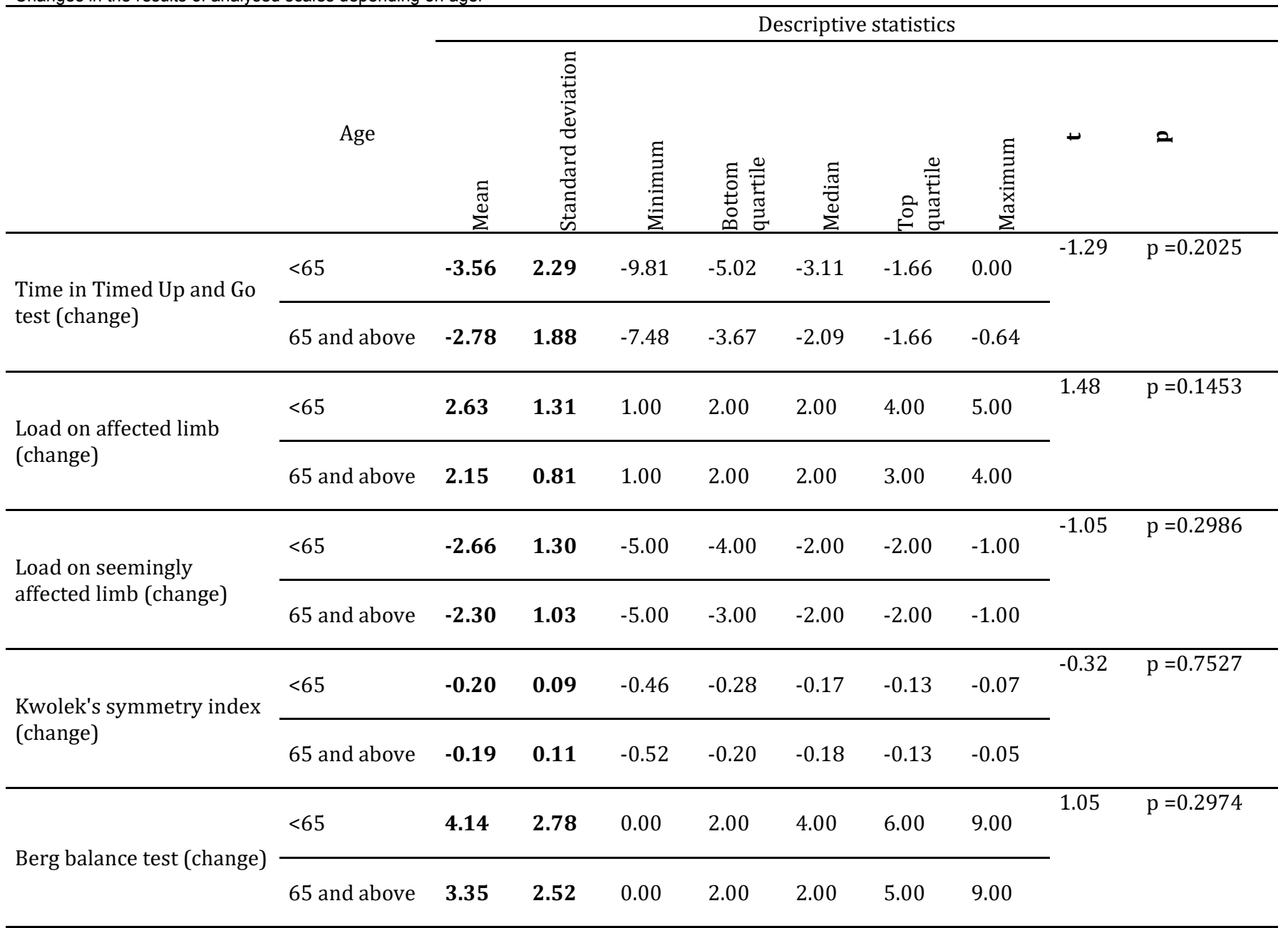

Time in the Timed Up and Go test (change) in the group aged $<65$ reached on average -3.56 sec., whereas in the group aged 65 and above the mean result reached -2.78 sec. No statistical significance was observed between the groups. Load on the affected limb (change) in the $<65$ group was on average $2.63 \mathrm{~kg}$, whereas in the group aged 65 and above the mean value reached $2.15 \mathrm{~kg}$. No statistical significance was observed between the groups.

Load on the seemingly affected limb (change) in the $<65$ group was on average $-2.66 \mathrm{~kg}$, whereas in group aged 65 and above the mean value reached $-2.3 \mathrm{~kg}$. No statistical significance was observed between the groups. Kwolek's symmetry index (change) in the $<65$ group was on average -0.2 pt., whereas in the group aged 65 and above the mean value reached $-0.19 \mathrm{pt}$.

No statistical significance was observed between the groups. The Berg balance test (change) in the $<65$ group was on average 4.14 pt., whereas in group aged 65 and above the mean value reached 3.35 pt. No statistical significance was observed between the groups (Tab. 5).

\section{DisCUSSION}

An inseparable element of a complex therapeutic procedure in the case of post-stroke patients is the evaluation of balance and postural stability. Conditions such as stroke cause vast neurological deficits in patients as a result of damage to the central nervous system. Impairment of physiological structures responsible for maintaining balance involves higher risk of collapse, disturbs the sense of security among patients and significantly reduces their quality of life.

Disturbances in balance and body stability in patients after ischemic cerebral stroke intensify their disability and reduce the chances of restoring independence $[11,12]$. According to numerous authors, one of the forms of rehabilitation which responds to the expectations of patients struggling with the effects of stroke is the method of proprioceptive neuromuscular facilitation (PNF).

Studies conducted by the team of Fedak D. et al. [13] on the group of 32 post-stroke patients subjected to a 12-week PNF rehabilitation programme indicate an improvement in the ability to maintain balance when in a standing position, as confirmed by the results obtained in the posturography test. Moreover, the effectiveness of the PNF method in patients after ischemic stroke is proved by results obtained in the research conducted by Suszyńskie K. et al. [14].

The test group was comprised of 20 hospitalised patients ( 15 women and 5 men) aged between 49 and 86 years. The conducted tests showed improvement both in muscular strength and tension, as well as in restoring 
capabilities in everyday activities. The obtained own research results find confirmation in studies carried out by the team of Kalisz K. et al. [15]. Neither the age nor the time from incident occurrence in the group of post-stroke patients affected progress in the rehabilitation of balance impairment.

\section{Conclusions}

1. The age and period elapsed from the incident do not have a statistically significant effect on the progress in the rehabilitation of balance and body stability impairment in the group of patients after ischemic cerebral stroke.
1. The results obtained in the Timed Up and Go test, tandem balance test, Kwolek's symmetry index and the Berg balance test, performed before and after the 4-week rehabilitation programme, indicate considerably better results in patients facilitated by the PNF method as compared with classic kinesitherapy.

2. A high correlation level was noted with regard to results obtained before and after the therapy in all of the utilised scales and tests.

\title{
BibLIOGRAPHY
}

2. Żyniewska-Banaszak B., Cichocki P. Rehabilitation procedure in acute ischemic cerebral stroke. Czynniki Ryzyka 2009; (1): 30-3.

3. Adamczyk K. Pro-health education of post-stroke patients. Problemy Medycyny Społecznej 2001; 31-37.

4. Sienkiewicz-Jarosz H., Głuszkiewicz M., Pniewski J. et al.: Decline of 30 day case fatality for stroke between 1991/1992 and 2005, comparison of data from population based studies. J. Neurol. 2006; 253 (2): 16-17.

5. Prusiński A, Vascular cerebral diseases. In: Neurologia Praktyczna,PZWL, Warsaw 2003;209-235.

6. Bogucki M., Gierczyński J., Gryglewicz J., Karczewicz E., Zalewska H. Cerebral stroke: social and economic consequences. Warsaw, Uczelnia Łazarskiego 2013; 110.

7. Członkowska A. Rehabilitation procedure following cerebral stroke: Report of an Expert Team of the National Stroke Prevention and Treatment Programme. Neurologia i Neurochirurgia Polska 2001; (6): 1-31.

8. Sharman M., Cresswell A., Riek S. Proprioceptive Neuromuscular Facilitation Stretching - Mechanisms and Clinical Implications. Sports Medicine 2006; 36 (11): 929-939.

9. Pasiut Sz., Banach M., Longawa K. et al. Post-stroke rehabilitation according to PNF method with and without the use of botulin toxin - case study. Rehabilitacja Medyczna 2005; 9 (1): 21-29

10. Sarzyńska-Długosz I. Development of care of post-stroke patients in Poland in the years between 2003-2012. Warsaw, Instytut Psychiatrii i Neurologii $2013 ; 154$.

11. Wolny T., Saulicz E., Gnat R. The application of PNF method in post-stroke patients. Rehabilitacja w Praktyce 2008; (3): $32-36$

12. Mazur R., Kozubski W., Prusiński A. Clinical neurology basics for medicine students. Wydawnictwo Lekarskie PZWL 1999.

13. Opara J., Sztokfisz J., Orkiszewska - Mokry K. Clinical evaluation of balance. Rehabilitacja w Praktyce 2010; (4): 18 - 20.

14. Fedak D., Latała B., Otfinowski J., Zajdel K. Assessent of the effects of physiotherapy on balance in standing position in post-stroke patients determined on the basis of posturography. Acta Bio-Optica et Informatica Medica 2010; (3): 16.

15. Suszyński K, Kaniewski O, Górka D. et al. The effect of PNF therapy on the process of motor improvement in patients after ischemic cerebral stroke localised in left hemisphere in the period of intense rehabilitation. Annales Academiae Medicae Silesiensis.2014;68(5):294-301.

16. Kalisz K, Kalisz Z, Hagner-Derengowska M, Zukow W, Trela E. Balance assessment in post-stroke patients on the basis of selected scales and tests. Journal of Health Sciences 2012;2(4):141-177.

\author{
dr med. Magdalena Jaworska \\ 28-400 Pińczów \\ ul. Nowy Świat $7 / 65$ \\ e-mail: magjaworska227@gmail.com
}

